\title{
FORMAÇÃO CONTINUADA DE PROFESSORES QUE ENSINAM MATEMÁTICA: conta e reconta para resolver problemas
}

\author{
CONTINUED EDUCATION OF MATHEMATICS TEACHERS: \\ counts and accounts to solve problems \\ FORMACIÓN CONTINUADA DE PROFESORES QUE ENSEÑAN \\ MATEMÁTICAS: cuenta y recuenta para resolver problemas
}

\author{
Maria das Graças Bezerra Barreto \\ Doutora em Educação Matemática da Universidade Anhanguera de São Paulo (UNIAN). \\ São Paulo-SP, Brasil \\ magrabela@uol.com.br \\ Maria Elisabette Brisola Prado Brito \\ Professora Doutora da Universidade Anhanguera de São Paulo (UNIAN). \\ São Paulo-SP, Brasil \\ bette.prado@gmail.com \\ Angélica Fontoura Garcia Silva \\ Professora Doutora da Universidade Anhanguera de São Paulo (UNIAN). \\ São Paulo-SP, Brasil \\ angelicafontoura@gmail.com
}

Resumo: Esse artigo tem como objetivo analisar o conhecimento do conteúdo matemático e dos alunos explicitados por professoras atuantes nos anos iniciais da Educação Básica durante um processo formativo. Trata-se de uma parceria entre a Universidade e a Escola que promoveu estudos, vivências, observações e análises da prática docente. Esta pesquisa, de caráter qualitativo, envolveu a formação de sete professoras dentro da escola pertencente à Diretoria Regional de Educação de São Miguel Paulista, da Secretaria Municipal de Educação de São Paulo. A análise dos dados se pautou em autores da formação do professor, como, Ball. Thames e Phelps, Schön, Zeichner e Serrrazina e em autores que discutem mais especificamente a aprendizagem de Matemática, tais como, Vergnaud, Brizuela, Moreno, Nunes e Bryant entre outros. A análise desta investigação mostrou que o processo formativo, desenvolvido na perspectiva colaborativa contribuiu para a ressignificação de conhecimentos sobre contagem e resolução de problemas aditivos e seu ensino, sobretudo acerca das estratégias utilizadas pelos estudantes. Observou-se ainda, uma postura investigativa das professoras participantes sobre as discussões teóricas e suas eventuais aplicações práticas.

Palavras-chave: Conhecimento Profissional. Prática Docente. Contagem. Problemas Aditivos.

\begin{abstract}
This article aims to analyze how the knowledge of mathematics content and of students is expressed by early elementary school teachers during a development process. The study is a partnership between the university and the school where the readings, experiences, observations and teacher's practice analysis took place. This research uses a qualitative approach and involved the development of seven teachers of a designated school, which belongs to the Regional Educational Directory of Sao Miguel Paulista linked to Sao Paulo's Municipal Education Department. Data analysis was based on teacher development authors such as Ball, Thames and Phelps, Schon, Zeichner and Serrrazina, and on authors who specifically discuss mathematical teaching, such as Vergnaud, Brizuela, Moreno, Nunes and Bryant, among others. The analysis of this investigation showed that the development process taken under the collaborative perspective contributed to re-signify knowledge about counting and solving addition problems and their teaching, mainly with regard to the strategies used by students. It was also noticed the investigative attitude demonstrated by the participating teachers about the theoretical discussions and their possible practical applications.
\end{abstract}

Keywords: Professional knowledge. Teaching Practice. Counting. Addition Problems

Resumen: Ese artículo tiene como objetivo analizar el conocimiento del contenido matemático y de los alumnos explicitados por profesoras actuantes en los años iniciales de la Educación Básica durante un proceso de formación. Se trata de una alianza entre la Universidad y la Escuela que promovió estudios, vivencias, observaciones y análisis de la práctica docente. Este estudio, de carácter cualitativo, involucró la formación de siete profesoras dentro de la escuela perteneciente al Directorio Regional de Educación de São Miguel Paulista, de la Secretaría Municipal de Educación de São Paulo. El análisis de los datos se basó en autores de la formación del profesor, como Ball, Thames y Phelps, Schon, Zeichner y Serrrazina y en autores que discuten más específicamente el aprendizaje de Matemáticas, tales como Vergnaud, Brizuela, Moreno, Nunes y Bryant entre otros. El análisis de esta investigación mostró que el proceso 
de formación, desarrollado en la perspectiva colaborativa contribuyó para la resignificación de conocimientos sobre cuenta y resolución de problemas adictivos y su enseñanza, principalmente acerca de las estrategias utilizadas por los estudiantes. Se observó también una postura investigativa de las profesoras participantes sobre las discusiones teóricas y sus eventuales aplicaciones prácticas.

Palabras claves: Conocimiento profesional. Práctica docente. Cuenta. Problemas adictivos.

\section{INTRODUÇÃO}

Em nossa trajetória como formadoras de professores que ensinam matemática nos anos iniciais, as "rodas de conversa" foram se tornando pouco a pouco, um espaço de diálogo que desvelou pensares, pesares e fazeres dos professores participantes e deu a oportunidade de escutar a si mesmo e do outro os saberes e as práticas matemáticas. Esses instantes preciosos permitiram que professores e formadores ouvissem e relatassem com entusiasmo os procedimentos de seus alunos, suas práticas e intervenções. Ao mesmo tempo, os professores expressavam em seus gestos as dificuldades encontradas, camuflavam os medos e titubeavam ao explicitar as dúvidas ao ensinar matemática. Era possível perceber no silêncio velado diante de algumas atividades propostas, uma ausência de voz na tentativa de dissimular conflitos internos diante dos conhecimentos ou desconhecimentos tanto do conteúdo matemático como pedagógico desse mesmo conteúdo.

Esse contato deu-nos indícios de como algumas ações formadoras tem disseminado dúvidas, ao invés de colaborar de extirpar as quebras de silêncio, angústias e dificuldades reveladas e enfrentadas pelos professores nas aulas de matemática, principalmente ao resolverem problemas matemáticos. A argumentação para justificar a dificuldade recorre para a incompreensão da linguagem contida nos enunciados textuais dos problemas, a insegurança frente aos procedimentos de solução encontrados e o obstáculo mais evidente, o domínio ou não da língua materna.

Essas observações desencadearam um refletir de como e quais problematizações estão sendo realizadas na sala de aula e como os professores compreendem e interveem nas estratégias de contagem de seus alunos e também na resolução de problemas. Essas questões nos instigaram em observar o Conhecimento profissional docente na perspectiva de Ball, Thames e Phelps (2008). Esse artigo tem como objetivo analisar o conhecimento do conteúdo matemático e dos alunos explicitados por professoras atuantes nos anos iniciais da Educação Básica durante um processo formativo.

\section{FORMAÇÃO CONTINUADA: espaço de compreensão e reflexão}

A Formação Continuada de Matemática tem sido vista pelos professores como sendo a oportunidade de compreender seus saberes matemáticos e a possibilidade de conhecer caminhos colaboradores para modificar e remodelar saberes ou fazeres ao ensinar Matemática (FIORENTINI, 2003; BOAVIDA, 2005; GARCIA SILVA, SERRAZINA; CAMPOS, 2014). Essas expectativas exigiram estratégias metodológicas envolvendo olhares mais atentos e compreensivos para os conhecimentos matemáticos apresentados pelos professores participantes e situações de aprendizagem que permitissem a explicitação e, eventualmente, a reformulação e ampliação de conhecimentos do conteúdo e do estudante na perspectiva de Ball, Thames e Phelps (2008).

Os autores consideram que esse tipo de conhecimento e a associação entre o domínio do professor sobre o conteúdo matemático e o conhecimento acerca da realidade dos alunos. Neste contexto, o docente seria capaz de prever que tipos de respostas os estudantes podem apresentar, reconhecer quais as dificuldades por eles enfrentadas com base nos erros que cometeram, além de abordar contraexemplos e contra-argumentos para discutir com seus alunos, de modo a guiá-los no aprendizado (BALL, THAMES; PHELPS, 2008).

Com base em tais princípios, investigamos um curso de formação continuada realizado em horário coletivo de escolas municipais de São Paulo, participantes da pesquisa. A ação investigativa e formativa envolveu sete professoras que lecionam Matemática para os anos iniciais. O curso tinha como intuito principal analisar a influência das formações continuadas de Matemática no processo de mudanças das práticas de sala de aula e, nesse contexto, sala de aula entendida como um ambiente favorável à percepção e exploração de caminhos praticados, escolhas teóricas, de descobertas (professor e aluno) e do imediato ocorrido.

Nesse sentido, essa formação continuada oferecida no âmbito escolar precisou tornar-se um espaço instigador de práticas reflexivas e aos poucos, construir uma relação de confiabilidade e 
cumplicidade favorecendo relatos e trocas de experiências. As professoras foram impulsionadas a olhar suas práticas com abertura, generosidade e compreensão.

Neste ambiente de estudo e reflexão compartilhou-se nos momentos de análise reflexiva da prática, relatos ou situações das aulas realizadas pelas sete professoras, denominadas: Raquel, Roseane, Angela, Cora, Marina, Cecília e Lygia ${ }^{1}$, e aos diálogos sobre os reais problemas enfrentados ao ensinar Matemática nos anos iniciais.

Desta maneira, buscamos a construção de um processo formador que possibilitasse vivências e análises referentes ao ensino e aprendizagem do conteúdo matemático propiciando a reflexão sobre práticas diferenciadas.

Esse ambiente formador permitiu desenvolver, como formadores de professor, uma atitude investigativa, uma escuta atenta e um olhar observador. Ao investigarmos o nosso fazer formador incentivávamos a investigação na sala de aula, problematizando os saberes das professoras e de seus alunos e discutindo intervenções. Para estruturá-la buscamos nas ideias de Schön (1992) os esclarecimentos para provocar esse movimento reflexivo dentro e fora da sala de aula. Ampliamos o olhar de Schön (1992) para o contexto social, considerando os estudos de Zeichner (1993; 2000).

Dessa forma, nossa busca foi pela reflexão que despertasse no grupo de professores maior atenção para o conhecimento matemático dos alunos, pensando e repensando cada fala para poder perceber minúcias até então desvalorizadas. Organizamos e reformulamos atividades matemáticas que validassem as hipóteses levantadas sobre como aluno pensa e faz, bem como, desafiassem as professoras a explorar outros caminhos. As tarefas realizadas com os alunos favoreciam 0 desenvolvimento do registro e reflexão sobre a importância das anotações dos momentos mais significativos que foram utilizados como subsídio nas discussões ocorridas durante a formação coletiva.

No coletivo da escola a ação formadora estimulava o falar das próprias experiências compartilhando os erros, fracassos e êxitos, buscando compreender como os estudantes aprendem matemática. Assim, superavam as resistências e reinterpretavam a situação se abrindo para rever caminhos e permitindo-se o direito de fazer de outro jeito, modificando a realidade vivida. As discussões teóricas serviram para compreender os pressupostos ideológicos que alicerçavam as práticas realizadas.

Afinal, instigar professores a serem reflexivos envolveu uma relação interpessoal com o grupo e a ressignificação de papeis, assim como de um ambiente colaborador, o qual propiciou a comunicação entre os pares e o compartilhamento das análises sobre o conteúdo matemático envolvido e a forma de ensinar este conteúdo visando o aprendizado dos alunos.

Para isso, as professoras redefiniram o seu papel como autoridade e detentora do saber e combateram o isolamento da profissão educativa, enfrentando o medo e o erro, partilhando os diferentes desafios, especialmente, o de como despertar a curiosidade dos alunos em saber mais. Para Zeichner (2000) nossa preocupação precisa voltar-se para o fato de que "não é se os professores são reflexivos, mas como estão refletindo e sobre o que estão refletindo" (ZEICHNER, 2000, p. 12).

Daí a importância de a formação contemplar momentos coletivos de reflexão entre as professoras de modo que possam reconstituir, conforme destaca Zeichner (2000) os processos de ensinar e de aprender dos alunos. Processo este que, segundo Ball, Thames e Phelps (2008) requer o conhecimento do conteúdo especializado do professor. No decorrer da pesquisa, percebemos o quanto a análise da narrativa da trajetória profissional e as entrevistas semiestruturadas colaboraram para a compreensão da trajetória pedagógica de cada professora. Os registros escritos da elaboração ou seleção de sequências de atividades realizadas com e pela professora e do acompanhamento em sala de aula e da observação do desempenho dessas professoras nos encontros de formação se constituíram em documentos valorosos que subsidiaram a escrita de desta pesquisa e as abordagens metodológicas durante o processo de formação.

\section{CONTA E RECONTA}

Apresentamos a seguir quatro episódios representativos do processo de formação. O primeiro episódio refere-se ao ensino do Sistema de Numeração Decimal e retomada de conceitos. Para isso, foi provocada uma discussão sobre o entendimento e valorização das notações numéricas provisórias apresentadas pelos alunos como resposta a algumas atividades propostas. Notações

Pseudônimo em homenagem às mulheres escritoras e ou poetisas brasileiras. 
numéricas consideradas durante muito tempo, um erro muito grave, justificado pela desatenção dos alunos.

Para fomentar esta discussão foram propostas situações problematizadoras baseadas nos estudos de Brizuela (2006) com relação à escrita numérica imperfeita e como elas não reproduzem as muitas reflexões que os alunos realizam para dar significado ao funcionamento do sistema de numeração escrita. Para a autora as produções numéricas dos alunos revelam convenções padronizadas para justificar partes desconhecidas ou não lembradas. Essa compreensão é afrontada pela prática comum utilizada na escola. Uma escrita numérica que preenche folhas e folhas com números iniciados pela unidade e ampliados para cada nova ordem estudada. Como podemos perceber na fala das professoras:

Raquel: Muitos alunos escrevem as listagens de números do 1 até o 30 ou 50 e sabem contar oralmente até 60 , mas no ditado apresenta uma escrita numérica cheia de erros. Eu não entendo isso.

Angela: Veja aquilo que lemos no texto [referindo-se no artigo de Brizuela], parece que nossos alunos pensam sobre os números mesmo antes de virem para escola.

Cora: Eu vejo que os meus aprendem escrever primeiro os números terminados por zero como ela diz [referindo-se a autora].

Raquel: aquela proposta de analisar tabelas [referindo ao quadro numérico] com mais números pode ajudar as crianças a perceber regularidades.

[Todas professoras concordaram]

Roseane: Então acho que minha prática de pedir para que os alunos escrevam e repitam os números, não adianta muito...

Raquel: Isso que eu estava dizendo. Os alunos, do mesmo jeito que em Português, já têm hipóteses sobre a escrita dos números e a gente não leva em conta, precisamos de outras formas de chamar atenção para [as características] o sistema de numeral decimal. Olhar para o quadro numérico, é uma boa alternativa.

Ficou evidenciado no diálogo das professoras, que elas entenderam que o "preenchimento de folhas e folhas" pode restringir a compreensão dos alunos em relação às características dos diferentes intervalos da sequência. Na perspectiva de Ball, Thames e Pheps (2008), observamos que os estudos teóricos e análise de situações do dia a dia de sala de aula do grupo de professoras, possibilitaram o entendimento que a prática de "preenchimento de folhas e folhas" com numerais não favoreceria a compreensão do estudante a respeito das características do Sistema de Numeração Decimal.

Aos poucos as professoras foram percebendo também que a contagem de uma sequência numérica, na perspectiva de Vergnaud (2009), precisaria ser mais bem compreendida e detectada. Os alunos ao escreverem uma sequência precisam ter avançado do nível da simples recitação e contagem. Na recitação de números, os alunos falam a palavra certa na ordem em que sabem. A contagem, um processo mais elaborado, exige uma correspondência entre os objetos da coleção, a sequência numérica falada, os gestos das mãos acompanhados e os movimentos dos olhos. Para o autor a contagem é a primeira forma de aplicação numérica, vai além de saber recitar. A recitação não garante saber contar elementos de um conjunto.

Isso parece também ter sido observado pelas professoras, conforme os relatos a seguir:

Lygia: Nossa! Eu sempre achei que bastava meu aluno recitar para eu ter certeza que ele conta direitinho.

Raquel: Mas se a gente perceber ele [o aluno] precisa acompanhar com o dedinho, com os olhos. Isso é correspondência o que mesmo?

Lygia: biunívoca não é o que a pesquisadora falou?

Pesquisadora: Isso mesmo!

Roseane: Isso mesmo, cada bola é apontada pelo dedinho dele. 
Notamos que os estudos de Vergnaud (2009) suscitaram discussões a respeito da relação biunívoca tão presente na atividade de contagem. Dando continuidade ao assunto, foi discutido com o grupo de professoras sobre a importância de os alunos se apropriarem de alguns princípios para realizarem a contagem e o contato com coleções diferenciadas. Para apoiar os estudos realizados foram oferecidos textos baseados em Nunes e Bryant (1997), Moreno (2006), Castro e Rodrigues (2008) para a compreensão desses princípios e organização de atividades que promovessem avanços na aprendizagem numérica dos alunos.

Os estudos permitiram que no coletivo na roda de conversa algumas situações fossem contadas pelas professoras sobre alguns destaques retirados da leitura, como mostra o relato a seguir:

Cecília: o aluno ao contar coleções, precisa contar todos os objetos e contá-los apenas uma única vez". Eu tenho alguns alunos que contam os objetos das coleções e se perdem. Eles contam mais de uma vez o mesmo objeto. Vou ficar mais atenta.

Nesse caso é possível perceber que a professora Cecília, chama a atenção para o princípio da contagem que considera a necessidade de cada objeto uma única vez. Com relação ao destaque existe uma ordem fixa para falar os nomes dos números da sequência e que o último termo indica o total de objetos contados. A professora Cora relatou um fato observado em sala de aula:

Cora: Eu tenho dois alunos que quando eles contam os carrinhos ou lápis sempre olham para a ordem que ele ocupa. Eu pedi para que um deles me desse oito. Ele me deu somente um carrinho, dizendo: "aqui o oito, professora". Eu fiquei sem entender na hora. Não falei nada. Agora eu estou entendo o que aconteceu. [referindo-se ao fato de que o aluno apresentou à professora o oitavo carrinho].

Analisando o ocorrido é possível perceber que as professoras observavam alguns dos resultados apontados pelos teóricos como por exemplo o fato de a criança contar o mesmo objeto mais do que uma vez ou levar em conta a posição do objeto na sequência ao invés de sua quantidade.

Acompreensão desses princípios fomentou uma mudança de prática: as professoras passaram a oferecer aos alunos mais atividades de contagem, pois na medida em que os alunos vivenciassem situações diferenciadas poderiam perceber outras estratégias de contagem consideradas "mais eficientes" para descobrir a quantidade de qualquer coleção de objetos.

Dessa maneira, a contagem passou a ser incorporada a rotina dos alunos e foram oferecidos diferentes situações e momentos pelas professoras como pudemos perceber no planejamento que foram compartilhados nos encontros coletivos.

Observamos que para as professoras, até aquele instante, contar era uma situação enfrentada com tranquilidade pelos alunos, como ilustra o relato da professora a seguir:

Cora: Afinal, eles sempre estão contando objetos, coisas em suas casas. Eles não terão nenhuma dificuldade.

A ação de observar atentamente como os alunos realizariam a contagem era a grande novidade a ser explorada pelas professoras, especialmente porque elas deveriam problematizar mais as atividades de forma que lhes possibilitasse a observar os conhecimentos numéricos e as estratégias mobilizadas pelos estudantes diante das situações apresentadas.

A primeira a realizar a tarefa de observar a contagem em sala de aula e relatar o ocorrido foi a professora Raquel, do $2^{\circ}$ Ano. Ela escolheu realizar o projeto "Coleção de Tampinhas de garrafas pet" com o propósito de analisar como seus alunos contavam objetos em coleções móveis. Organizou os em duplas e ao perceber que algumas duplas, um dos parceiros não havia levado tampinha, compartilhou o problema com a turma.

Perguntou aos alunos:

Como será possível fazer a tarefa, se nem todos os alunos haviam trazido tampinhas?

Os alunos responderam de imediato:

A gente dá um pouco de tampinhas para quem não trouxe. 
Como os alunos trouxeram mais tampinhas, rapidamente se disponibilizaram a distribuir para os demais colegas, como ilustra a figura 1 a seguir:

Figura 1 - Contagem da Coleção de Tampinhas (momento-1)

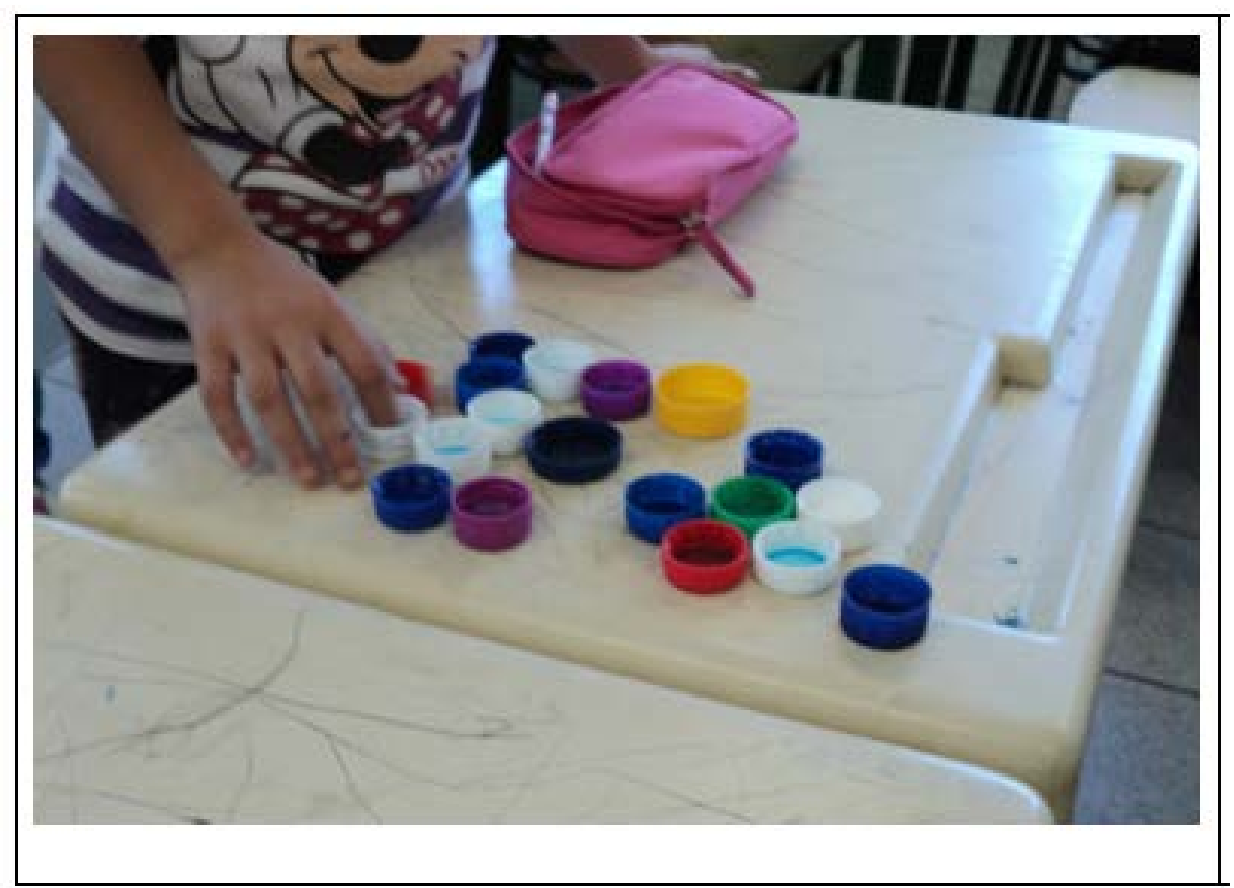

Fonte: Barreto (2011).

O inesperado está sempre presente em sala de aula e deve ser aproveitado. Uma das alunas resolveu dividir suas tampinhas com a colega em partes iguais, em dois grupos como podemos observar na figura 1. Para essa divisão, a contagem realizada foi feita por agrupamentos de seis em seis para cada grupo, quando o número ficou pequeno foi diminuindo gradativamente, o agrupamento de distribuição, 3 em 3, 2 em 2 e de 1 e 1. O uso do agrupamento para contar coleções com quantidade grandes de objetos é considerado um processo de evolução dentro da contagem.

Na figura 2 podemos ver as coleções recebidas pela colega, que ao conferir separou todas as tampinhas para a contagem um a um.

Figura 2 - Contagem da Coleção de Tampinhas (momento-2)

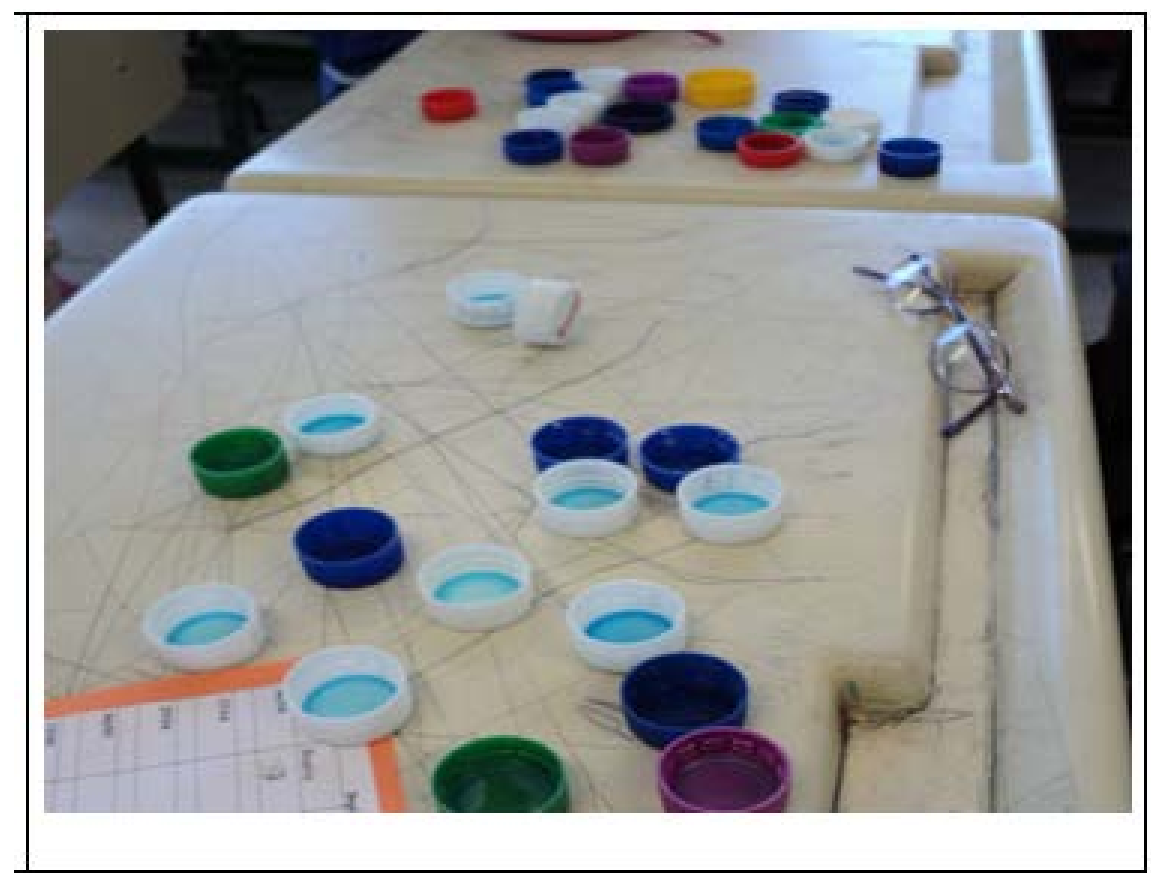

Fonte: Barreto (2011). 
A professora ao perceber o ocorrido, apesar do objetivo não ser divisão, aproveitou o momento para problematizar, colocando no grupo a seguinte questão:

Raquel: Como foi feito a divisão das tampinhas com os colegas? Quantas tampinhas cada aluno ganhou? Houve sobra?

Durante o encontro coletivo, relatou no grupo a sua admiração ao perceber a noção de divisão apresentadas por alguns de seus alunos, conforme mostra o trecho a seguir>

Raquel: Eles não realizaram uma divisão apenas de $1 \mathrm{em} 1$ como a maioria. Eles realizaram um ato de dividir mais avançado apoiado nos agrupamentos e com certeza, nas recitações de 2 em 2, de 3 em 3, de 6 em 6 e outras que tenho realizado diariamente.

Pesquisadora: Isso é muito bom, mas vamos pensar um pouco mais sobre o ocorrido do ponto de vista da Matemática. A divisão que eles realizaram, qual foi?

Raquel: Eles repartiram em partes iguais.

Roseane: Os alunos foram fazendo a distribuição usando o agrupamento e vejam que não fizeram de 1 em 1.

Raquel esclareceu ainda: Estava acompanhando a mesma turma no $2^{\circ}$ ano e acreditava que as atividades de contagem com coleções fixas realizadas pelos alunos no Caderno de Apoio e Aprendizagem do ano anterior tinham contribuído para um repertório de contagem que apoiou o pensar daqueles alunos.

Analisando o diálogo resultante da apresentação da professora Raquel é possível observar que as professoras notaram a possibilidade de trabalhar com a divisão no sentido de partição. Houve certo espanto ao perceberem que as crianças realizavam os procedimentos de agrupamento, mas nos pareceu não ser um motivo de estranhamento do grupo o fato de a divisão na perspectiva da partição estar presente já nesse segmento de ensino. Observando o ocorrido neste primeiro episódio, na perspectiva de Ball, Thames e Phelps (2008) foi possível perceber que as participantes deste estudo ampliaram seus conhecimentos a respeito da contagem e seu ensino.

A continuidade do projeto realizada sem a nossa observação, constituiu em preenchimentos semanais da tabela com a quantidade de tampinhas trazidas pelos alunos. Esses momentos envolveram a problematização de quantidades grandes de tampinhas obtidas pelas duplas, a leitura e escrita de números que ainda não estiveram presentes em suas atividades.

Outro episódio, por nós selecionado diz respeito a um trabalho com a representação gráfica.

A professora Roseane, do $1^{\circ} \mathrm{Ano}$, com um grupo de alunos na maioria com 5 anos e alguns meses, realizou como atividade para observar que estratégias de contagem os alunos utilizariam a organização de dados de pesquisa em gráfico e relatou como se deu ocorrido:

Roseane: Em uma roda, conversei como meus alunos sobre a organização das respostas dadas por eles a pesquisa "Eu sou assim...". Expliquei para a classe como havia contado as respostas deles a pesquisa realizada em aulas anteriores e registrado na tabela como mostra a figura 3 . 
Figura 3 - Tabela da atividade "Eu sou assim..."

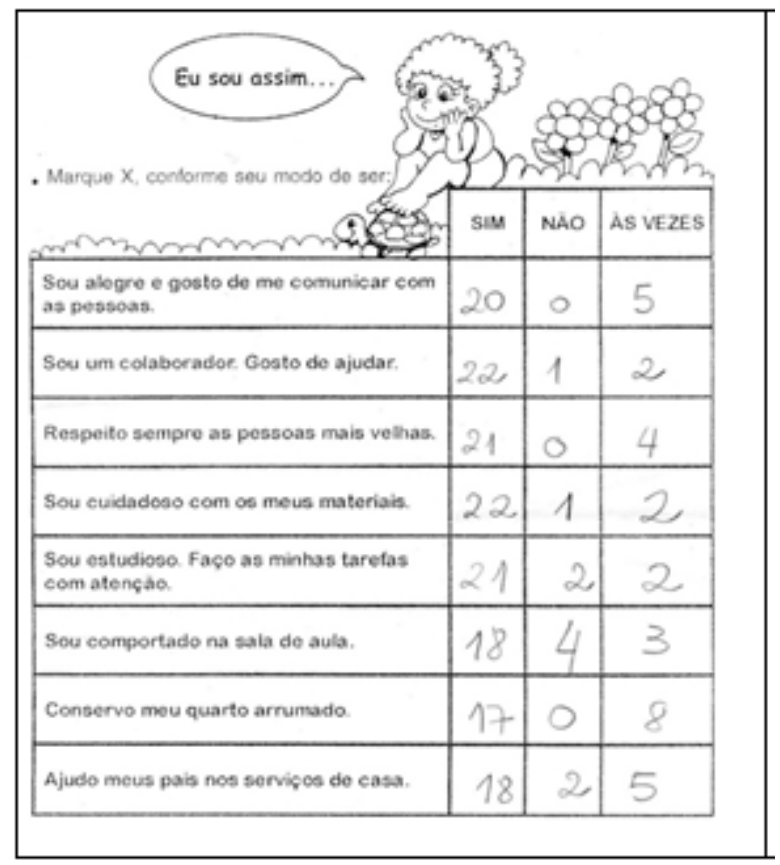

Fonte: Barreto (2011).

A pesquisadora comentou como a professora havia explorado com os alunos algumas questões: O que é gráfico? Alguém sabe?

Em seguida, a professora Roseane permitiu que todos os alunos falassem o que sabiam e pensavam sobre gráficos. Onde já havia visto. E continuou o seu relato:

Roseane: Depois da conversa com os alunos, entreguei uma filipeta para cada trio e uma folha quadriculada. A folha quadriculada trazia na linha horizontal as respostas que deveriam ser preenchidas, como mostra a figura 4.

Figura 4 - Construção do gráfico da atividade "Eu sou assim..."

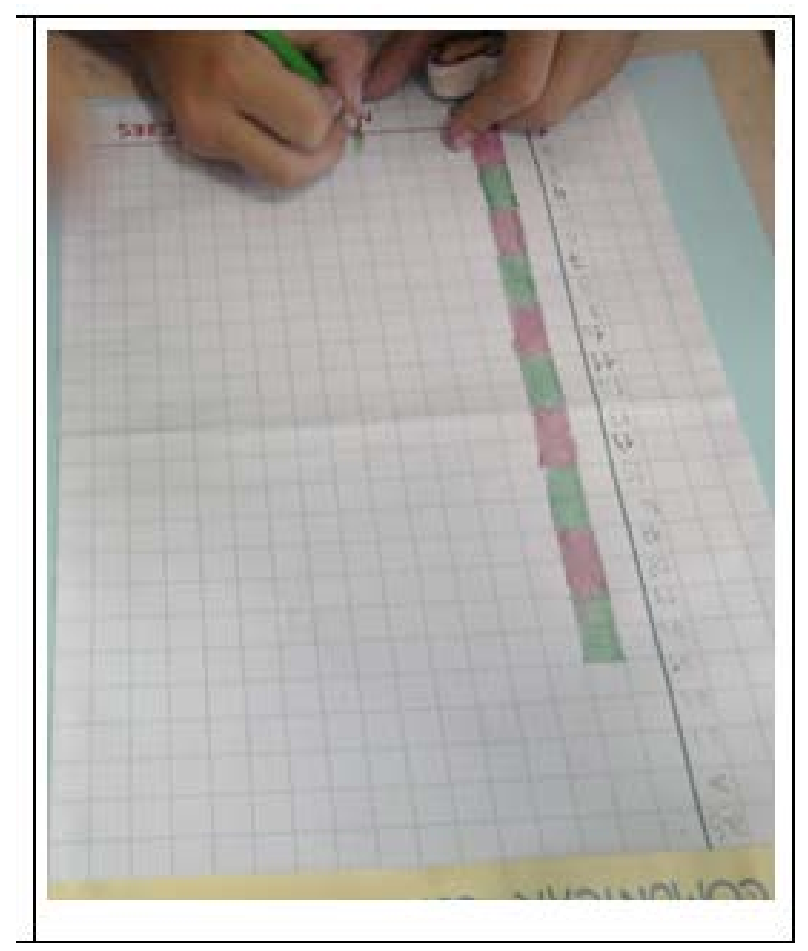

Fonte: Barreto (2011). 
Roseane: Os alunos enumeraram o eixo vertical em trio e cada elemento deveria pintar uma coluna com os dados recebidos.

Roseane comentou: os alunos participam com entusiasmo. Percebi que os trios não pintavam as quantidades indicadas nas filipetas recebidas relacionando-as com a enumeração destacada na linha vertical.

Os números colocados ao lado eram desconsiderados. Ao pintar a coluna os trios contavam os quadradinhos até obter a quantidade indicada na filipeta.

A professora observou que a contagem foi realizada de um em um em todos os trios e após a realização da tarefa afixou todos os gráficos no quadro e convidou todos os alunos a observarem os gráficos com suas respostas, conforme podemos observar a figura 5 , a seguir:

Figura 5 - Gráficos da atividade "Eu sou assim..."

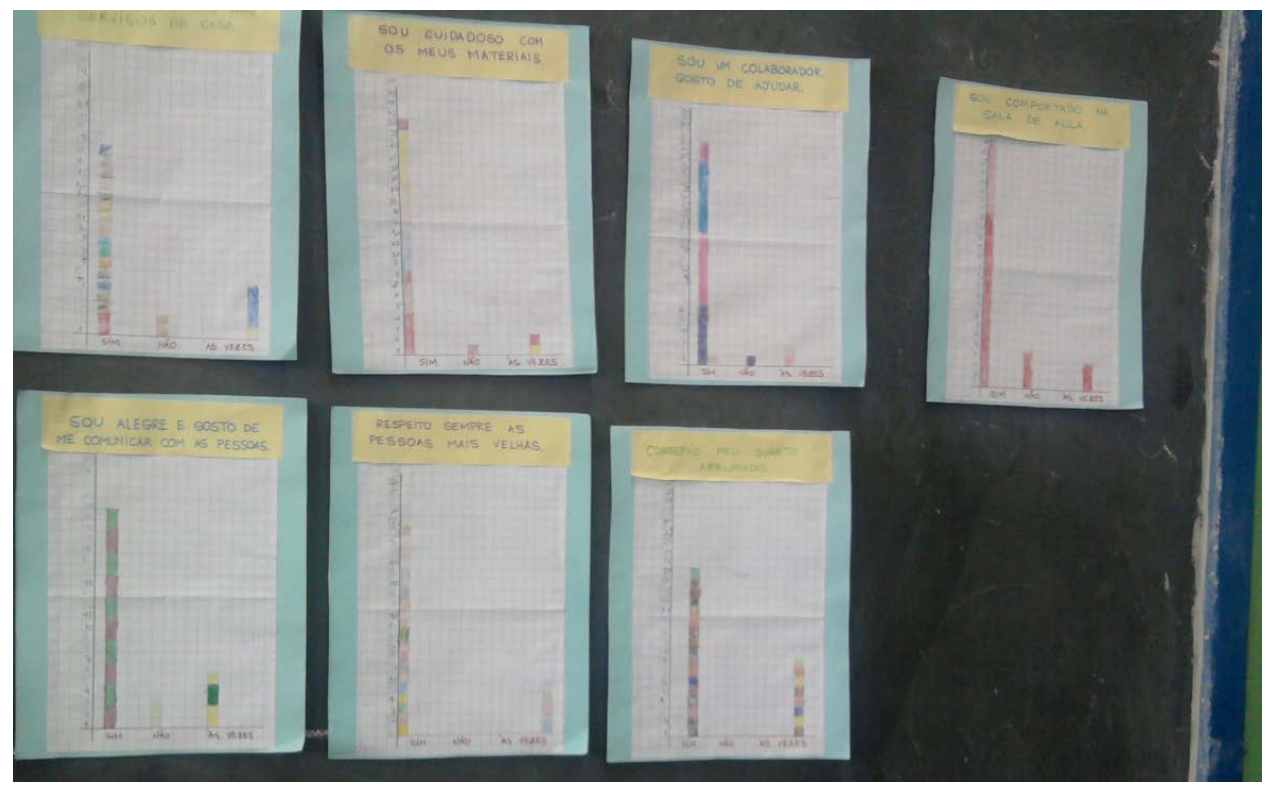

Fonte: Barreto (2011).

Após a observação de todos, os alunos foram questionados sobre o que tinham sentido ao realizar a tarefa. A professora fez a seguinte indagação: Os números ao lado ajudaram a pintar 0 gráfico? Como nós sabemos quantos alunos responderam sim para o gráfico 6 ?

Roseane: Os alunos responderam que haviam contado os quadradinhos. Eu os alertei para a importância da enumeração da linha vertical, e o auxílio dela para a leitura do gráfico. Mostrei para eles como fazia em outro gráfico. Mesmo assim, o aluno que respondeu a segunda questão sobre o total de alunos que responderam sim, foi até o gráfico e novamente contou os quadradinhos, desconsiderando a relação numérica.

A professora contou que chamou novamente a atenção de todos para os números colocados no eixo vertical e perguntou a eles sobre a ausência da coluna do não no mesmo gráfico. E finalizou declarando:

Eles observaram a professora em silêncio, sem nenhum comentário.

Esta atividade elaborada pela professora e discutida posteriormente, no coletivo, em uma reflexão sobre sua ação, permitiu que todos percebessem a necessidade de explorar novamente a confecção de gráficos para organizarem dados de pesquisa e outros já prontos para serem interpretados pelos alunos. Ao término da análise, outros encaminhamentos de exploração do material foram propostos na troca de experiências.

$\mathrm{O}$ coletivo concluiu que a atividade tinha sido uma situação de aprendizagem interessante e motivadora que envolveu todos os alunos na realização da tarefa e exigiu trabalho de colaboração da turma. Uma das professoras do grupo verbalizou ao final: 
Roseane: Fiquei muito admirada com o desempenho dos alunos.

Confesso a vocês que estava muito preocupada se daria conta das intervenções que fossem necessárias para atender as dúvidas e dificuldade esperadas na realização da tarefa.

Percebi que meus alunos realizaram a tarefa com autonomia.

Observamos que a professora estava sempre atenta aos alunos e preocupou-se em circular pela classe e problematizar as situações em cada trio, mantendo-os interessados na realização e curiosos pelo resultado final da atividade.

Analisando a proposta apresentada é possível perceber que a professora Roseane se utilizou da representação gráfica e da tabela para desenvolver a atividade de contagem. É possível perceber que há uma preocupação por parte da professora em trazer situações próximas ao aluno, uma vez que ela procurou caracterizar a sala de aula. Nesse sentido, existe aproximações com estudos como os Carraher, Schliemann e Nemirovsky (1995) e Ainley, Nardi e Pratt (1998), por exemplo, que também observaram preocupação por parte de professores em trabalhar com assuntos do cotidiano das crianças, Notamos que a professora se preocupou em discutir com as crianças os elementos constituintes do gráfico como os eixos.

Mais duas professoras relataram para os seus grupos de formação as atividades realizadas com contagem, as quais serão descritas no episódio 3.

A professora Cora relatou para o seu grupo a atividade de contagem realizada no Caderno de Apoio e Aprendizagem ( $1^{\circ}$ Ano, p. 30) conforme podemos observar nas figuras 6 e 7.

Figuras 6 e 7 - Contagem de coleções fixas

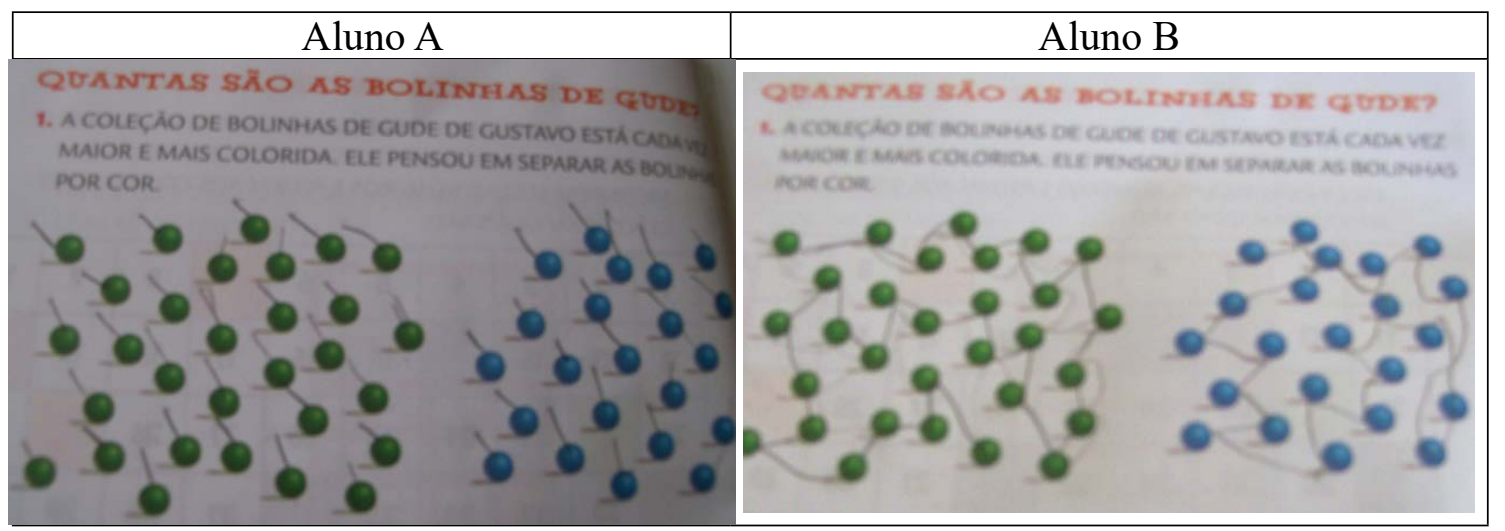

Fonte: Barreto (2011).

Cora: Eu esperava que meus alunos criassem maneiras pessoais para garantir a contagem das coleções fixas de objetos espalhados.

Observei que mesmo em grupos diferentes, a contagem era sempre de um em um.

Os alunos que começaram a riscar as bolinhas já contadas ou separavam por agrupamentos de 2 em 2 ou 5 em 5 e desistiam após comparar o resultado com o colega, retornavam para a contagem de um em um.

A professora colocou ainda, que muitos alunos se perderam e ao serem questionados se haviam contado todas as bolinhas, afirmavam convictos que sim, apesar dos resultados não coincidirem. 
Cora: Observei que um dos princípios da contagem, contar bolinhas uma única vez, fora uma dificuldade enfrentada por muitos. As estratégias escolhidas por eles não ajudaram a encontrar o resultado.

Roseane: Na minha sala isso também ocorre. Por isso precisamos dar mais atividades desse tipo para os alunos.

Raquel: É, eles precisam se organizar para não contar mais de uma vez cada bolinha, vejam o aluno $B$

Cora: Por isso, é que precisamos diversificar, contar coleções móveis e fixas. Tem aluno que faz direitinho, mas outros precisam de mais experiência.

Pesquisadora: Mas vocês perceberam que cada aluno utilizou uma estratégia. [as professoras ficaram alguns minutos observando as estratégias dos alunos]

Cora: $O$ aluno $A$ marcou todas as bolinhas e não percebeu quando marcou duas vezes a mesma. Já o aluno B ligou as bolinhas, teve boa estratégia.

Analisando o diálogo na perspectiva de Ball, Thames e Phelps (2008), é possível observar que as professoras associaram o domínio do conteúdo matemático - princípios da contagem - e o conhecimento sobre a realidade dos estudantes e sobre o ensino, para analisar as estratégias dos dois alunos.

Finalizando o assunto, foi destacada a necessidade de os alunos vivenciarem situações diferenciadas de contagem. Em alguns momentos eles precisam contar coleções móveis ampliando a compreensão das propriedades de contagem, contar uma única vez cada objeto e falar na ordem certa (NUNES; BRYANT, 1996). Em outro, contar coleções fixas e por último, seriam desafiados a contarem coleções com objetos variados.

Discutimos que o esperado seria que após a realização de atividades diferenciadas os alunos passassem a utilizar agrupamentos como um procedimento econômico para contar quantidades grandes. Essa situação pode ser antecipada com as práticas diárias de recitações realizadas de 2 em 2, de 5 em 5 e assim por diante, partindo do 1 ou de valores variados. Após esta explanação a professora Lygia afirma: Eu que achava que as recitações eram pura decoreba. É possível notar que a reflexão sobre a prática possibilitou estabelecer relações com a teoria.

Nunes e Bryant (1996, p. 53) propõem situações nas quais os alunos possam utilizar a "contagem para resolver problemas e[...] possam fazer inferências com base na contagem [...] e transformar a contagem numa ferramenta de pensamento".

Essa afirmação desencadeou mais um momento de reflexão - $4^{\circ}$ episódio na formação coletiva, na perspectiva de Zeichner (1993; 2000). Discutiu-se o conceito de problema e como eles favorecem a aplicação dos princípios de contagem na busca de soluções. Explorou-se a proposta de resolver problema como um caminho desafiador possibilitando colocar em prática os conhecimentos matemáticos, criando procedimentos e validando escolhas para a solução.

Nas discussões sobre os procedimentos pessoais dos alunos as respostas e questionamentos de alguns grupos foram:

Os alunos ao resolverem problemas fazem tracinhos e contam, dando a resposta sem realizar a operação.

Como podemos avançar com alunos que ainda utilizam, procedimentos tão "precários"?

Como lidar com os alunos que apresentavam dificuldade em interpretar e resolver situaçõesproblema?

Como interpretar os procedimentos propostos por eles?

Alguns não resolvem problemas, pois não sabem ler direito, outros desconhecem a conta que ajuda a encontrar o resultado.

Todos ficaram interessados pela argumentação da pesquisadora. Ela continuou a problematizar: O que vocês entendem por problema? Poderíamos considerá-lo um texto, ou não? Há diferença entre resolver um problema e resolver um exercício? A atividade é a mesma?

As respostas obtidas foram: 
FORMAÇÃO CONTINUADA DE PROFESSORES QUE ENSINAM MATEMÁTICA: conta e reconta para resolver problemas Maria das Graças Bezerra Barreto; Maria Elisabette Brisola Prado Brito; Angélica Fontoura Garcia Silva

Para ser problema tem que ter números e uma pergunta.

Parece um texto, mas não tenho certeza.

Observamos quanto a ser um texto, pairavam dúvidas..., mas prosseguiram com as reflexões:

Podemos considerar um texto..., mas ele tem números.

Eu nunca pensei em um problema como texto, ele precisa ser interpretado, não é?

Uma situação que a gente não sabe a resposta, é preciso pensar, organizar um caminho.

Estas são algumas das afirmações verbalizadas, e em uníssonos: "um desafio". A impressão dada, o fato de ser desafio diferenciava o problema, tornava-o especial. As ideias apresentadas eram confusas e representavam a dificuldade dos professores em oferecer problemas para os alunos.

Em seguida, alguns problemas propostos pelos professores foram analisados. Houve destaque para aqueles problemas em que as quantidades são representadas por desenhos de objetos. Modelos retirados dos livros didáticos e selecionados pela maioria dos professores dos anos iniciais. As professoras justificaram:

O desenho ajuda os alunos menores a encontrar o resultado mais rápido e é menos cansativo fazer a atividade

Apoiamo-nos em Moreno (2006, p. 49), considerando que o professor deve "propor ao aluno situações de aprendizagem para que este produza seus conhecimentos partindo da busca pessoal dos procedimentos que lhe permitirão encontrar a resposta para o problema apresentado". Nesta perspectiva, os alunos precisam ser estimulados a apresentarem procedimentos pessoais. Após confiarem em seus procedimentos de solução apresentados deve gradativamente, ser levado a compreender a importância do uso de procedimentos mais econômicos, o uso das técnicas convencionais.

Nesse sentido, possivelmente durante a formação procuramos discutir os pressupostos dos estudos de Moreno (2006) e isso favoreceu a reflexão sobre a prática:

Raquel: Eu achava que os problemas com desenhos ajudariam meus alunos. Não pensei que poderiam prejudicá-los.

Cecília: Mas se formos pensar ela tem razão [Moreno] pois se não dermos chance para o aluno arrumar estratégia ele só irá contar.

As professoras, possivelmente, estavam tirando a oportunidade de os alunos apresentarem diferentes procedimentos de solução e demonstrarem seus conhecimentos. Ao mesmo tempo, poderiam estar impedindo de vivenciarem etapas importantes para a compreensão matemática dos problemas propostos, os procedimentos pessoais. Neste episódio observamos indícios de alguns dos pressupostos indicados por Zeichner (1993) serem levados em conta pelas professoras participantes deste estudo uma vez que elas assumiram uma atitude reflexiva em relação as estratégias utilizadas pelos alunos e não sentiam-se ao expor sua forma de pensar, ou o que o autor define por "suas teorias práticas, para si próprio e para os seus colegas" (ZEICHNER, 1993, p.21), tanto quando estavam apoiadas nas experiências como nos pressupostos teóricos.

Outra situação observada durante a formação foi a atitude dos professores ao analisarem os problemas propostos para depois serem aplicados em sala de aula. Eles alteravam os dados numéricos, como se seus alunos não tivessem condições de resolver problemas com números maiores. Para contrapor a postura de usar números pequenos para os alunos menores desencadeando soluções rápidas e sem desafios. Nesse sentido as professoras foram desafiadas a formularem problemas com números desconhecidos para seus alunos.

As professoras, Roseane e Cora aceitaram o desafio, apesar dos ares de incredulidade, elaboraram quatro problemas com estrutura aditiva envolvendo as ideias de transformação aditiva e subtrativa e comparação. 
A figura 8 mostra a atividade realizada pelo aluno A que foi discutida no coletivo do grupo de professoras.

Figuras 8 - Estratégia de contagem na solução de problemas

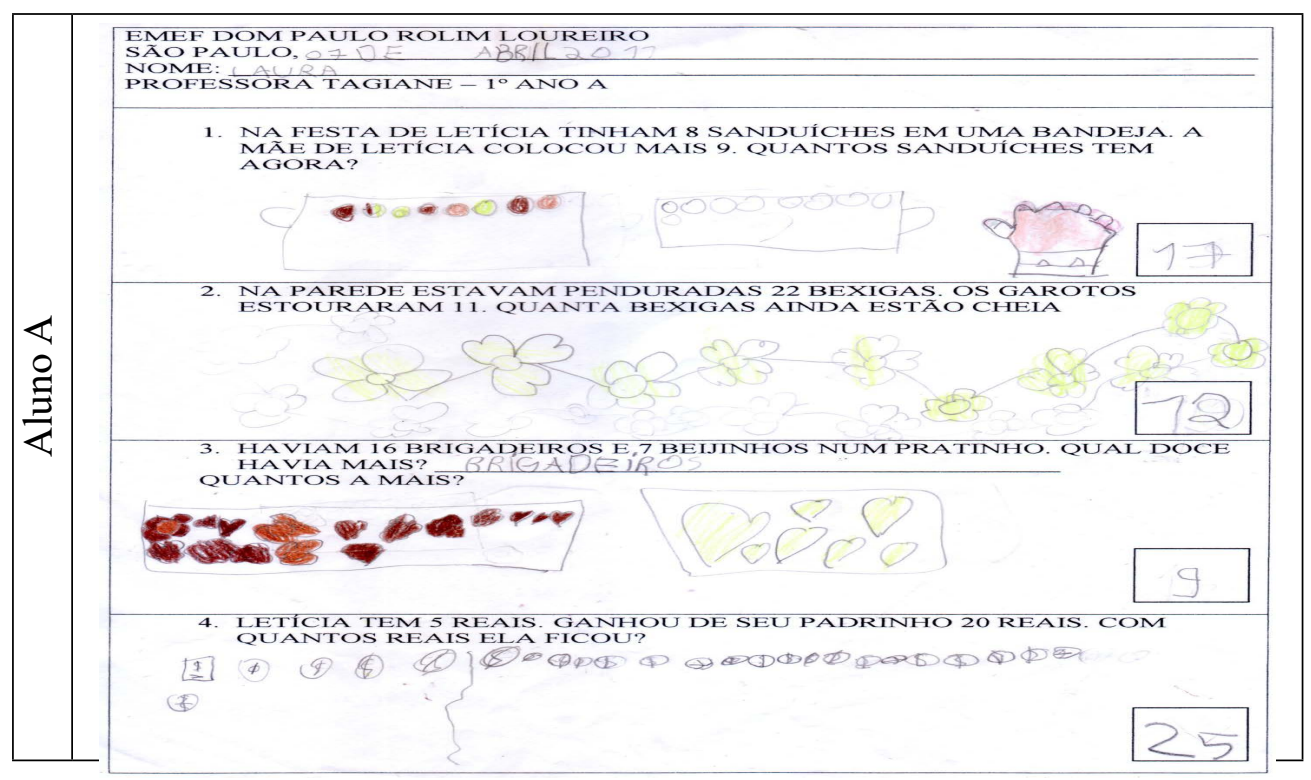

Fonte: Barreto (2011).

Observa-se que nesta atividade foram utilizados os diferentes procedimentos de solução de contagem aliada ao desenho como forma de confirmação dos resultados. Para a análise coletiva no grupo foi discutido os estudos dos pesquisadores Gray e Tall (1994) que apresentam um processo de evolução observado na situação de contagem para resolver situações aditivas. Para os autores a "noção de adição envolve uma série de procedimentos diferentes" (GRAY; TALL, 1994, p.123), inicia-se por estratégias mais simples, de "juntar todos" e avança para as mais complexas, a "sobrecontagem". Na sobrecontagem o primeiro número é considerado um todo e o segundo número é interpretado como um procedimento de dupla contagem - a contagem e o controle dos números extras a serem contados. Gradativamente, a escolha acaba recaindo sobre o número maior, uma estratégia mais econômica. Posteriormente, utilizam um fato conhecido e muito significativo, a composição e decomposição dos componentes de uma adição. Percebem que eles colaboram para encontrar o resultado, desvinculando-se da contagem.

O aluno A utilizou a ideia de transformação e apoiou a solução no "juntar todos" para resolver o problema com estrutura aditiva, como mostrado na figura 8. O aluno, desenhou uma bandeja para cada grupo de sanduíches separadamente, preocupado em representar com detalhe os objetos. Contou a primeira quantidade, depois a $2^{\mathrm{a}}$ quantidade e, finalmente, contou todos juntos. No segundo problema, colocou o todo e retirou a quantidade do total.

A solução do aluno B mostrada na figura 9, segundo a professora Cora, apresentou uma solução diferente de todos os colegas da turma. Após a leitura dos problemas realizada pela professora deu a resposta imediatamente.

Figura 9 - Contagem na solução de problemas. Mãozinha 


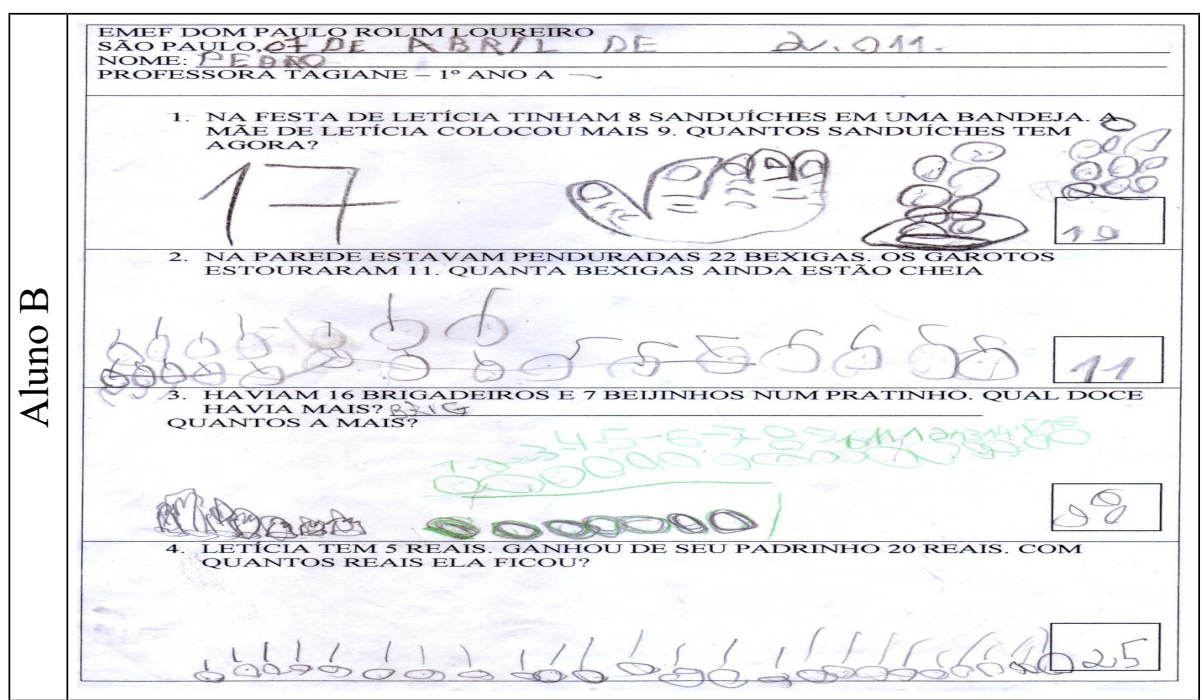

Fonte: Barreto (2011).

A apresentação do desenho foi realizada por solicitação da professora Cora. Ela exigiu um registro como comprovação do resultado verbalizado. A prova solicitada mereceu diferentes "jeitos" como garantia de fazer o esperado pela professora, conforme relato a seguir:

Cora: Quando questionei como ele tinha descoberto o resultado e o porquê do desenho da mão, explicou: Contei nos nove dedos e achei 17. Ele continuou: eu deixei o oito e contei nos dedos assim, mostrou nove dedos e contei 10,11,12,13, até o 17. Por isso eu desenhei a mão. E a primeira bandeja com os 9 sanduiches.

Depois ele contou que viu que os colegas haviam desenhado duas bandejas, voltou a sua carteira e desenhou a segunda bandeja.

A professor Cecilia percebeu que esse aluno apresentou um avanço em relação aos colegas: ele utilizou a sobrecontagem. Já a professora Lygia durante a discussão no coletivo do grupo destacou que no segundo problema o aluno não apresentou dificuldades, ele conta todos e corta as bexigas estouradas.

As professoras mostraram-se surpresas com os procedimentos apresentados por seus alunos e o resultado apresentou resultados além de suas expectativas. Os professores começaram a perceber a importância de ensinar por meio de problemas e como os alunos se tornam mais autônomos.

Observamos que anteriormente, as sete professoras apresentavam-se reticentes em deixar seus alunos realizarem autonomamente as atividades. Orientavam cada passo da atividade impedindo os alunos a escolherem suas próprias estratégias. Analisou-se no coletivo também, como a facilidade e a proteção impediam seus alunos de enfrentarem novos desafios e colocarem em prática seus conhecimentos. O quanto estavam bloqueando a oportunidade dos alunos de estabelecerem relações, dentro e fora da Matemática. Concluímos que muitas atitudes do professor o impedia de ser um mediador do processo de construção dos conhecimentos gerados nas salas de aula, aquele que mostra e apoia cada caminho. Aquele que permite que os alunos avancem a cada dia e os ajuda a tornarem-se cada vez mais autônomos.

\section{CONSIDERAÇÕES FINAIS}

O propósito desse artigo é de compartilhar algumas descobertas realizadas por nossa investigação. Muitas vezes o olhar investigativo se pauta em um observar trajetórias e estratégias usadas pelos professores. Há uma preocupação em manter o olhar supervisionado, para realizar uma interpretação com criticidade das posturas, os olhares, as falas e saberes praticados na sala de aula.

Percebemos nessa trajetória a necessidade de acrescentar a uma postura acadêmica esperada uma relação formadora-pesquisadora pautada na colaboração, respeito e confiabilidade. Essa relação foi firmando um diálogo que nos permitiu cumprir o nosso propósito principal de formador, 
o de desequilibrar, de desafiar, e de acolher. Para aos poucos, construir com os professores outros caminhos, práticas e difundir teorias sob o olhar investigativo e observador do pesquisador.

Uma parceria formadora e pesquisadora que reconheceu a escola como espaço de promover reflexão e apoiar as práticas dos professores. Reconheceu a sala de aula como um ambiente repleto de saberes diversificados e de não saberes explicitados. Ambos se mostraram como lugares promotores de aprendizagem e "ensinança". Ao mesmo tempo, espaços de formação onde o ouvir/ escutar e olhar/observar para refletir devem ser partilhados com o coletivo da escola na construção de outros caminhos e papeis que sejam mais desafiadores e investigativos. As estratégias diferenciadas devem ser mobilizadas e analisadas reflexivamente a cada passo para superar as dificuldades e ressignificar os problemas, sejam eles de Matemática ou de aprendizagem.

Nesse sentido, concluímos que a formação continuada aliada à pesquisa deve promover um processo de retroalimentação: diagnóstico subsidiado por teoria que promovem atividades práticas. Após análise, as práticas se tornam diagnósticos exigindo outras teorias para gerarem novas atividades práticas. Esse processo dinâmico e cíclico permite formadores/pesquisadores e professores/pesquisadores terem clareza de seus papéis e o reconhecimento de que investigações e análises reflexivas ao e sobre o ensinar Matemática valorizam e problematizam a provisoriedade dos conhecimentos matemáticos dos alunos dos anos iniciais promovendo a ampliação desses saberes.

Analisando os conhecimentos do conteúdo matemático e dos alunos explicitados por professoras atuantes nos anos iniciais da Educação Básica durante um processo formativo foi possível perceber que o contato com resultados de pesquisa permitiu que as professoras ampliassem seu olhar a respeito da contagem, observando as propriedades envolvidas na contagem e a necessidade de apresentar aos seus alunos situações variadas - fixas e móveis - de forma que pudessem favorecer a ampliação das estratégias dos estudantes. Ficou evidenciado também a compreensão de práticas equivocadas, como a restrição a compreensão dos alunos se a prática do professor for pautada somente no "preenchimento de folhas e folhas" com numerais, por exemplo. Com relação a contagem por meio da representação gráfica observou-se haver preocupação por parte dos professores em orientar os estudantes quanto aos componentes de um gráfico e estabelecer relação entre essa representação e a contagem. Além disso, para essa temática foi notória a preocupação com a apresentação de situações próximas ao cotidiano das crianças. Quanto a resolução de problemas foi possível observar que os estudos e reflexões conjuntas realizadas favoreceram o olhar do professor para as estratégias utilizadas pelos estudantes. 


\section{REFERÊNCIAS}

AINLEY, J. ; NARDI, E.; PRATT, D. Graphing as a computer-mediated tool. IN: Proceeding 22nd Annual Meeting of the International Group for the Psychology of Mathematics Education, v. 1, p. 243-258, South Africa. 1998.

BARRETO, M. G. B. A Formação Continuada de Matemática dos professores dos anos iniciais do Ensino Fundamental e seu impacto na prática de sala de aula. 2011. Dissertação (Mestrado) - Universidade Bandeirante de São Paulo. São Paulo: UNIBAN, 2011.

BALL D. L.; THAMES, M. H.; PHELPS, G. Content Knowledge for Teaching: What Makes it Special? New York: Journal of Teacher Education, v. 59, n. 5, p. 389-407, 2008. Disponível em:< http://jte.sagepub.com/>. Acesso em: 15 ago. 2011

BOAVIDA, A. N. R. A argumentação em Matemática: Investigando o trabalho de duas professoras em contexto de colaboração. 2005. Tese (Doutorado em Educação) - Departamento de Educação, Faculdade de Ciências. Universidade de Lisboa, Lisboa, 2005.

BRIZUELA, B. M. Desenvolvimento matemático na criança: explorando notações. Porto Alegre: Artmed, 2006.

CARRAHER, D., SCHLIEMANN, A.; NEMIROVSKY, R. Graphing Form Everyday Experience. Hands on!, v. 18, n. 2, 1995.

CASTRO, J. P.; RODRIGUES, M. O sentido de número no início da aprendizagem. In: BROCARDO, J., SERRAZINA, L., ROCHA, I. (org.). O Sentido do Número: reflexões que entrecruzam teoria e prática. Lisboa: Escolar Editora. Cap. 9, p. 117-1332008.

FIORENTINI, D. Formação de professores de matemática: explorando novos caminhos com outros olhares. Campinas: Mercado de Letras, 2003.

GARCIA-SILVA, A. F.; SERRAZINA, M. L.; CAMPOS, T. M. M. Formação Continuada de Professores que Lecionam Matemática: desenvolvendo a prática reflexiva docente. Bolema [online]. 2014, vol.28, n.50, pp.1505-1524. Disponível em: <http:// www.scielo.br/pdf/bolema/v28n50/1980-4415-bolema-28-50-1505.pdf>. Acesso em 29 nov. 2017
GRAY, E.M.; TALL, D. O. Duality, Ambiguity and Flexibility: A Proceptual View of Simple Arithmetic. 1994. Disponível em: <http://homepages.warwick. ac.uk/staff/David.Tall/pdfs/dot1994a-gray-jrme.pdf>. Acesso em 4 de ab. de 2012

MORENO, B. R. O ensino do número e do sistema de numeração na educação infantil e na $1^{\text {a }}$ série. In: PANIZZA, M. (Org.) Ensinar matemática na educação infantil e nas séries iniciais: análise e propostas. Porto Alegre: Artmed. cap. 3, p. 19-33. 2006

NUNES, T.; BRYANT, P. Crianças fazendo matemática. Porto Alegre: Artes Médicas. p. 244. 1997.

SERRAZINA, M. L., O professor e a Matemática. Mirandela - Caminhos para a investigação em Educação Matemática em Portugal. Bragança: SPCE, p. 111-127, 1998.

SCHÖN, D. A. Formar Professoras como Profissionais Reflexivos. In: Nóvoa, A. (coord.). Os Professores e a sua Formação. Lisboa, Portugal: Publicações Dom Quixote, Instituto de Inovação Educacional. p. 77-91, 1992.

VERGNAUD, G. A criança, a matemática e a realidade. Curitiba: Editora UFPR, p. 22, 2009.

ZEICHNER, K. M. A formação reflexiva de professores: ideias e práticas. Lisboa: Educa-Professores. 1993.

Formação de professores: contato direto com a realidade da escola. Belo Horizonte: Presença Pedagógica, v. 6, n. 34, p. 5-15, jul/ago. 2000. Disponível em: <http://www.presencapedagogica. com.br/capa6/entrevistas/34.pdf $>$. Acesso em: 19 ago. 2011. 